\title{
Perancangan System Smart Office Berbasis Internet of Things Politeknik Penerbangan Makassar
}

\author{
System Design of Smart Office-Based Internet of Things \\ Aviation Polytechnic of Makassar
}

\author{
Muhammad Agung Raharjo ${ }^{1}$, Fatmawati Sabur ${ }^{2}$ \\ muaraklatig77@gmail.com, fatmawatisaburatkp@gmail.com
}

Politeknik Penerbangan Makassar

\begin{abstract}
ABSTRAK
Permasalahan yang diangkat dalam penelitian ini yakni bagaimana penyelesaian masalah dalam penggunaan peralatan elekronik kantor agar lebih efisien dengan memanfaatkan teknologi internet sebagai media untuk mengontrol, AC, komputer, dan lampu. Terkadang kita masih mendapati suatu ruangan yang terdapat peralatan elekronik seperti AC, komputer, dan lampu masih dalam keaadan menyala padahal sudah tidak digunakan sehingga terkesan pemborosan dan tidak efisien, oleh karena itu dibutuhkan sebuah sistem smart office berbasis Internet of Things yang dapat mengatur dan mengontrol kondisi peralatan elektronik kantor dari mana saja melalui jaringan internet sehingga bisa bermanfaat untuk mengidentifikasi dan memantau apakah dalam keadaan menyala atau tidak menyala. Dengan sistem pengontrolan diharapkan dapat membantu untuk mengidentifikasi dan memantau dalam menyalamatikan perangkat elektronik secara remote melalui sebuah antarmuka pengguna. Penelitian ini bertujuan untuk merancang sistem smart office yang berbasis internet of things agar dapat digunakan untuk mengindentifikasi dan mengontrol peralatan elektronik kantor secara fleksibel. Hasil dari penelitian ini dapat menjadi masukan bagi manajemen pimpinan dalam pengambilan kebijakan dalam pengelolaan peralatan elektronik kantor yang lebih efisien.
\end{abstract}

Kata kunci: perancangan sistem; smart office; Internet of Things

\begin{abstract}
The problem that raised in this research is how to solve problems in using office electronic equipment to make it more efficient by utilizing internet technology as a medium for controlling, air conditioning, computers, and lights. Sometimes we still find a room that has electronic equipment such as air conditioning, computers, and lights that are still on even though they are not used so that it seems wasteful and inefficient, therefore we need an Internet of Things-based smart office system that can regulate and control conditions. office electronic equipment from anywhere via the internet network so that it can be useful for identifying and monitoring whether it is on or off. The control system is expected to help to identify and monitor the switching on and off of electronic devices remotely through a user interface. This research aims to design a smart office system based on the internet of things so that it can be used to flexibly identify and control office electronic equipment. The results of this study resulted in a prototype of a smart office system based on the internet of things that can help identify and control electronic equipment in the office.
\end{abstract}

Keywords: smart office; system design; Internet of Things 


\section{PENDAhULUAN}

Seiring dengan perkembangan teknologi dan internet, penggunaan IoT untuk perangkat elektronik kantor dapat kita lakukan secara otomatisasi sesuai dengan kondisi dan keinginan kita sehingga dapat dikontrol kapan dan di mana saja. Terkadang kita masih mendapati suatu ruangan yang terdapat peralatan elekronik seperti $\mathrm{AC}$, komputer, dan lampu masih dalam keaadan menyala padahal sudah tidak digunakan sehingga terkesan pemborosan dan tidak efisien, oleh karena itu dibutuhkan sebuah sistem yang dapat mengatur dan mengontrol kondisi dan keadaan ruang kerja. Teknologi masa depan yang dulu hanya bisa dibayangkan, kini sudah bisa diterapkan dan dirasakan berkat kemajuan teknologi dan komunikasi, penerapan teknologi ini tentu merupakan penggabungan beberapa teknologi diantaranya teknologi sensor, komunikasi tepat waktu (realtime), ataupun teknologi yang lain.

Politeknik Penerbangan (Poltekbang) Makassar adalah salah satu pendidikan tinggi dibawah naungan Kementerian Perhubungan (Prihatin, 2018; Rossydi \& Purbo, 2018). Poltekbang merupakan salah satu perguruan tinggi yang terus berinovasi dan bertransformasi menuju pengembangan konsep Smart Office dan Smart Campus, hal ini ditandai dengan komitmen dan kebijakan dari pimpinan dan seluruh stakeholder guna mendukung pengembangan dan peningkatan perangkat teknologi informasi baik dari segi infrastruktur maupun penggunaan software. Sebagai langkah awal menuju pengembangan konsep smart office dan Smart campus, maka perlu dilakukan inventarisasi perangkat elektronik yang dapat dikontrol penggunaannya sehingga bisa lebih fleksibel dan efisien. Penggunaan komputer, printer, AC, dan lampu di lingkungan Politeknik Penerbangan Makassar baik yang ada di gedung kantor maupun di gedung kelas perlu mendapat perhatian mengingat perangkat ini terdapat hampir di semua ruangan sehingga diperlukan sebuah sistem yang dapat membantu untuk memonitor perangkat tersebut dari satu tempat.

Berdasarkan latar belakang di atas dibutuhkan konsep sistem bagaimana memanfaatkan teknologi Internet of Thing (IoT) sebagai media untuk mengontrol perangkat elektronik di Politeknik Penerbangan Makassar.

Penelitian ini bertujuan untuk mengusulkan pemanfaatan teknologi Internet of Thing (IoT) dalam mengontrol perangkat elektronik kantor yaitu merancang prototype sistem smart office di Politeknik Penerbangan Makassar sehingga bisa lebih efisien dan fleksibel dalam penggunaanya.

\section{a. Internet of Things}

Internet of things (IoT) pertama kali ditemukan pada tahun 1999 oleh Kevin Ashton, merupakan teknologi yang memungkinkan benda-benda dan perangkat (device) disekitar kita terhubung melalui jaringan internet sehingga memudahkan kehidupan manusia, seperti smart home, smart office, health care system, monitoring system. Internet of Things (IOT) adalah struktur di mana objek, orang disediakan dengan identitas eksklusif dan kemampuan untuk pindah data melalui jaringan tanpa memerlukan dua arah antara manusia ke manusia yaitu sumber ke tujuan atau interaksi manusia ke komputer. (Burange \& Misalkar, 2015).

\section{b. Smart Office}

Sistem smart office adalah sistem aplikasi gabungan antara teknologi dan pelayanan yang di khususkan pada suatu kenyamanan kantor dengan fungsi yang bertujuan untuk meningkatkan efisiensi, keamanan pemilik serta karyawannya. Menurut Primawan Badri (Dell: 2017) mengungkap, ada empat keunggulan smart office yang mau tak mau harus diperhatikan industri perkantoran, yaitu: "1) Smart Office Mencerdaskan Pekerja; 2) Smart Office Jadi Ekosistem yang Sangat Terintegrasi; 3) Smart Office Dukung Kerja Remote; 4) Smart Office Menjaga Keamanan Pekerja.

Sedangkan penelitian yang dilakukan oleh Harun Sujadi, dkk. Menyimpulkan bahwa sistem Smart Office dapat mewujudkan kantor yang representatif sehingga meningkatkan kualitas dan efektifitas karyawan dalam bekerja. Konsep smart office berfokus pada orang-orang yang bekerja di dalamnya, sehingga mungkin akan berbeda-beda kebutuhan teknologi dan layanannya yang dibutuhkan untuk masingmasing kantor.

\section{METODE}

Penelitian ini merupakan jenis penelitian eksperimen. Dalam merancang sebuah prototype penggunaan peralatan elektronik kantor yang berbasis IoT, dilakukan dengan pengujian dan eksperimen rancangan sistem yang dibangun dengan mengambil referensi dari beberapa teori dan hasil penelitian, serta artikel ilmiah 
sebelumnya yang berkaitan dengan Smart Office. Tahapan penelitian yang dilakukan dapat dijelaskan sebagai berikut:

1) Studi Literatur

Pada tahap ini, dilakukan pencarian studi literatur tentang materi penelitian mengenai IoT dan Smart Office. Pencarian ini didasarkan pada teori yang berkaitan dengan penelitian yang telah dilakukan beserta teori yang berkembang saat ini.

2) Perancangan Perangkat Keras

Selanjutnya setelah dilakukan studi literatur kemudian dilakukan perancangan perangkat keras yang meliputi desain rangkaian elektronika berbasis IoT seperti penggunaan, NodeMCU, dan peralatan sensor dan relay.

3) Perancangan Perangkat Lunak

Perancangan perangkat lunak meliputi, desain layout aplikasi, dan pemprograman sistem.

4) Ujicoba

Pada tahap akhir dilakukan pengujian secara keseluruhan, untuk mengetahui rancangan perangkat baik hardware maupun software berfungsi dengan baik.

\section{a. Diagram Alir Perancangan}

Adapun diagram alir dari rancangan sistem smart office berbasis IoT sebagai berikut:

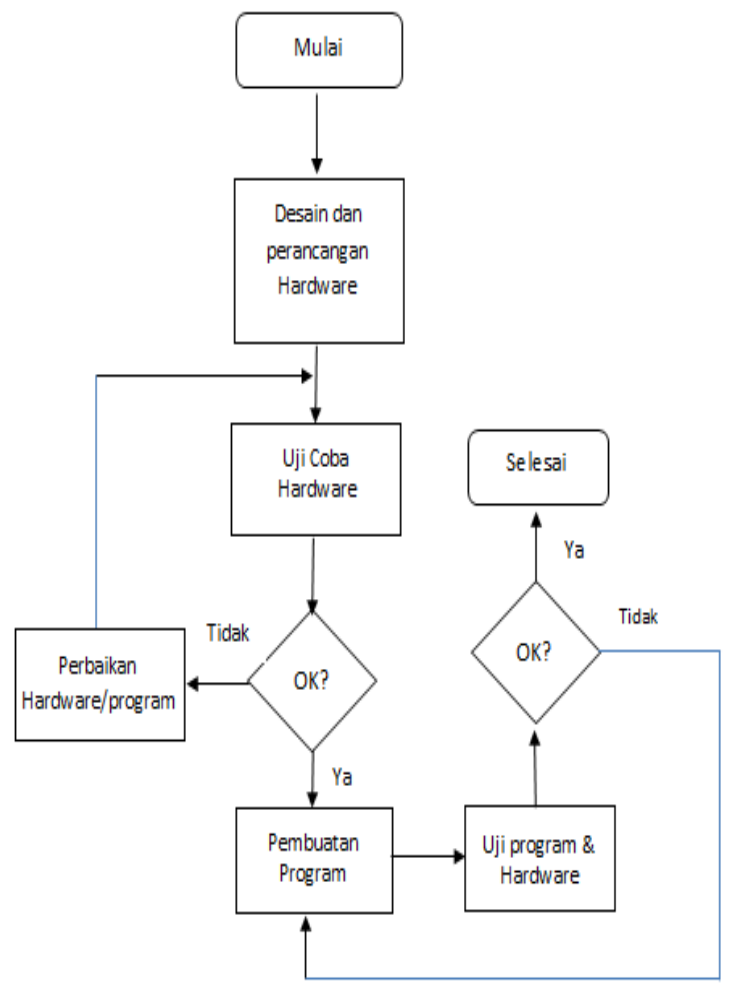

Gambar 1. Diagram Alir Perancangan Sistem

\section{b. Desain Model}

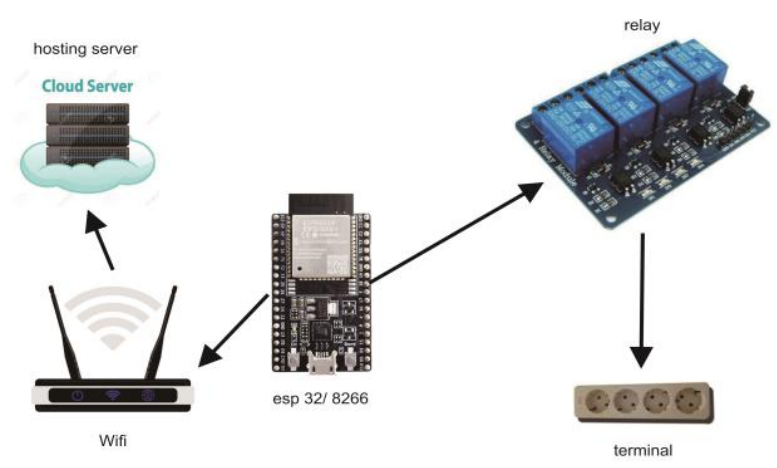

Gambar 2. Desain Model Sistem

\section{HASIL DAN PEMBAHASAN \\ a. Prototype Smart Office}

Prototype yang akan dirancang pada aplikasi smart office di Politeknik Penerbangan Makassar difokuskan pada gedung main building lantai 2 tepatnya di ruangan Keuangan, Umum dan Kerjasama. Adapun gambar skema prototype sistem smart office sebagai berikut :

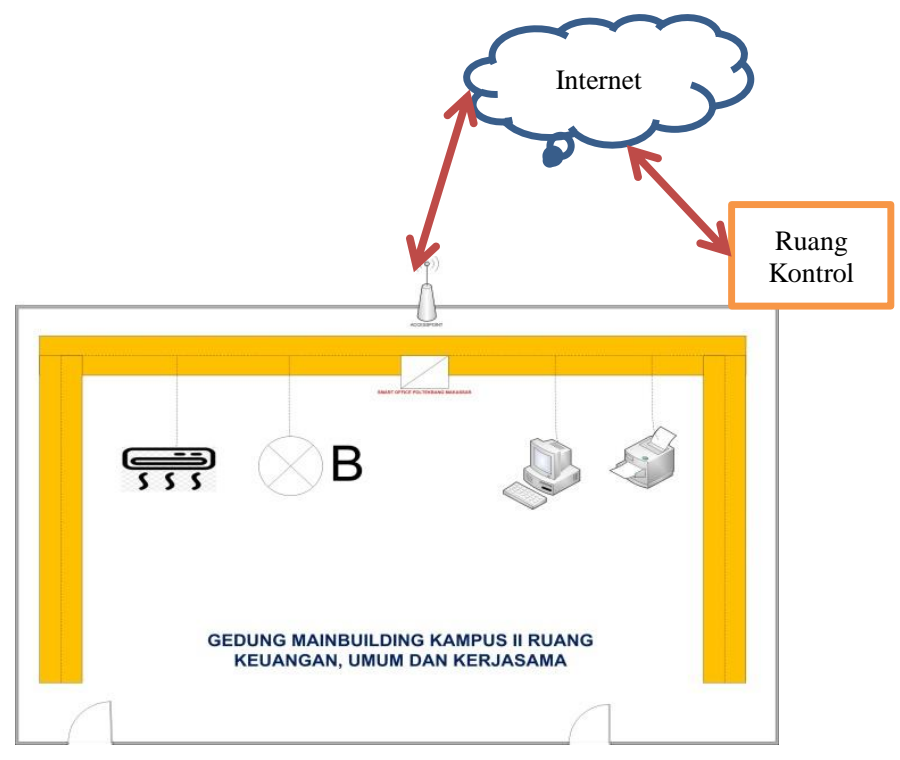

Gambar 3. Prototype Smart Office

Cara kerja dari sistem smart office sebagaimana gambar di atas yaitu sistem ini dapat melakukan pengontrolan terhadap peralatan elektronik kantor yang terkoneksi dalam sistem smart office melalui jaringan internet yang bisa dikontrol melalui ruangan pengontrolan maupun secara mobile sehingga lebih fleksibel dan memudahkan dalam pengontrolannya. Penggunaan hosting server akan berguna untuk menyimpan data aktif/tidaknya peralatan 
elektronik di kantor, yang kemudian dapat di akses melalui internet. Jaringan Wifi akan menjadi alat komunikasi agar Node MCU ESP 32/8266 dapat terhubung ke internet, yang kemudian mengambil data dari hosting server. Data yang didapat oleh Node MCU ESP 32/8266 akan di proses dan menghasilkan output ke relay. Relay akan berguna semacam saklar untuk terminal. Terminal yang akan di kontrol melalui relay akan terhubung dengan alat elektronik yang di gunakan di kantor.

\section{b. Kebutuhan Perangkat Keras (Hardware)}

Perangkat keras yang dibutuhkan untuk merancang prototype sistem smart office di Poltekbang Makassar terdiri dari :

1) Breadboard

adalah board yang digunakan untuk membuat rangkaian elektronik sementara dengan tujuan uji coba atau prototipe tanpa harus menyolder. Dengan memanfaatkan breadboard, komponen-komponen elektronik yang dipakai tidak akan rusak dan dapat digunakan kembali untuk membuat rangkaian yang lain.

2) NodeMCU ESP32/8266

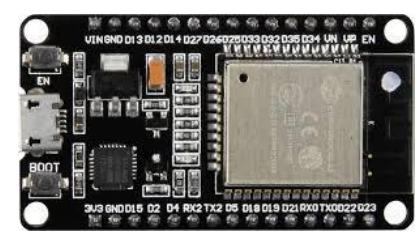

Gambar 4. Nodemcu Esp32/8266

Merupakan modul turunan pengembangan dari modul platform IoT (Internet of Things) keluarga ESP8266 tipe ESP-12. Secara fungsi modul ini hampir menyerupai dengan platform modul arduino, tetapi yang membedakan yaitu dikhususkan untuk "Connected to Internet"

3) Relay

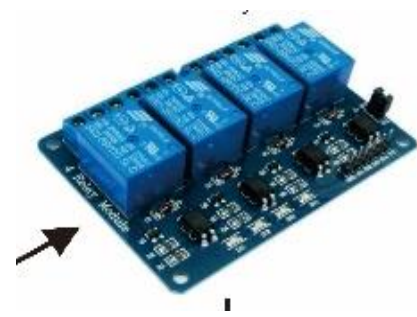

Gambar 5. Relay
Merupakan saklar (switch) yang dioperasikan secara listrik dan merupakan komponen Electromechanical (Elektromekanikal) yang terdiri dari 2 bagian utama yakni Elektromagnet (Coil) dan Mekanikal (seperangkat Kontak Saklar/Switch). Relay menggunakan Prinsip Elektromagnetik untuk menggerakkan Kontak Saklar sehingga dengan arus listrik yang kecil (low power) dapat menghantarkan listrik yang bertegangan lebih tinggi. Dalam penelitian ini menggunakan modul relay 4 chanel $5 \mathrm{~V}$.

4)Access point

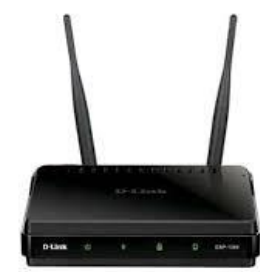

Gambar 6. Access point

Memiliki fungsi utama sebagai pemancar sinyal internet. Selain itu fungsi access point lainnya juga meliputi pengaturan konektivitas yang kompleks. Fungsi access point: Menggantikan fungsi hub yang menghubungkan jaringan lokal nirkabel dengan jaringan kabel.

\section{c. Kebutuhan Perangkat Lunak (Software)}

Perangkat lunak yang dibutuhkan untuk merancang prototype smart office sebagai berikut:

1) Arduino IDE (Integrated Development Environment) adalah software yang di gunakan untuk memprogram di arduino, dengan kata lain Arduino IDE sebagai media untuk memprogram board Arduino.

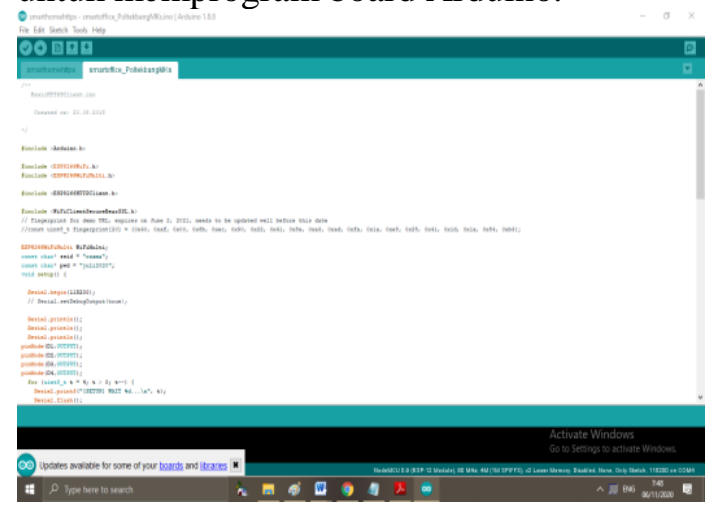

Gambar 7. Software Arduino Ide 
2) Android Studio adalah Lingkungan Pengembangan Terpadu (Integrated Development Environment/IDE) resmi untuk pengembangan aplikasi Android, yang didasarkan pada IntelliJ IDEA. Terapkan Perubahan untuk melakukan push pada perubahan kode dan resource ke aplikasi yang sedang berjalan tanpa memulai ulang aplikasi.

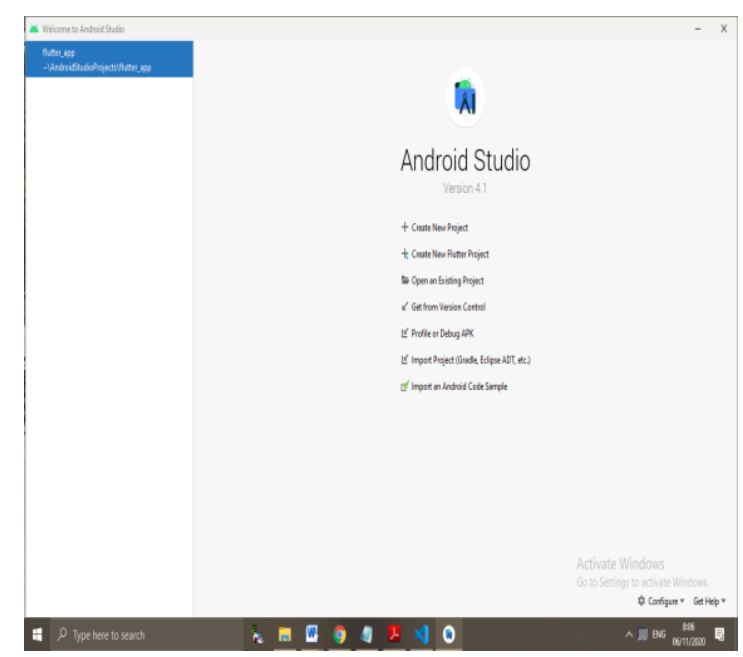

Gambar 8. Software Android Studio

\section{d. Hasil Rancangan Prototype Sistem Smart Office}

Hasil rancangan prototype dari sistem Smart Office terdiri dari rancangan Hardware dan software sebagai berikut:

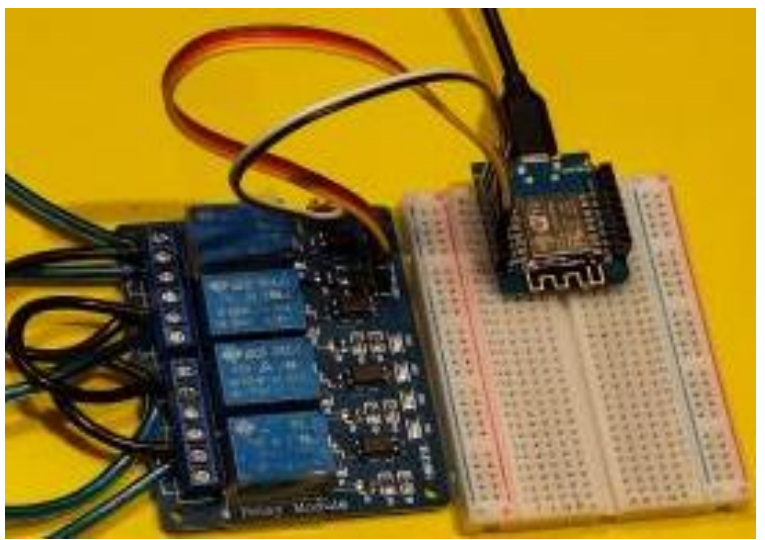

Gambar 9. Perangkat Hardware setelah dirangkai

Dari gambar di atas merupakan hasil rancangan dari kebutuhan hardware yang digunakan sebagai perangkat smart office, dimana proses pemasangan dari beberapa komponen disesuaikan dengan petunjuk tabel berikut:
Tabel 1. Posisi Pin Relay dan MCU

\begin{tabular}{ccc}
\hline NO & $\begin{array}{c}\text { PIN MCU NODE } \\
\text { ESP 32/8266 }\end{array}$ & $\begin{array}{c}\text { PIN RELAY 4- } \\
\text { CHANEL 5 V }\end{array}$ \\
\hline 1 & VOC & $5 \mathrm{~V}$ \\
2 & G & GND \\
3 & D4 & IN1 \\
4 & D3 & IN2 \\
5 & D2 & IN3 \\
6 & D1 & IN4 \\
\hline
\end{tabular}

Tabel di atas menunjukkan keterhubungan hardware antara pin MCU ESP 32/8266 dengan pin Relay 4-chanel:

\section{e. Hasil Rancangan Software Sistem Smart Office}

Perancangan perangkat lunak (software) sistem smart office dimulai dengan mendesain tampilan utama pada layar monitor yang nantinya digunakan sebagai interface antara aplikasi dan perangkat hardware sistem smart office yang telah dirangkai. Aplikasi yang telah dibuat akan dipasang pada perangkat mobile dalam hal ini menggunakan Handphone yang berfungsi sebagai media pengontrol.

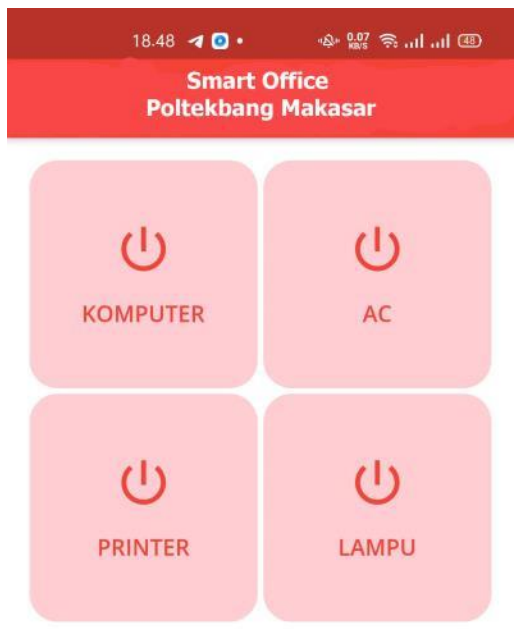

Gambar 10. Tampilan Utama Sistem Smart Office

Dari gambar di atas menunjukkan tampilan utama pada handphone yang digunakan sebagai interface dalam mengontrol peralatan elektronik di Politeknik Penerbangan Makassar. Peralatan elektronik kantor yang menjadi objek pengontrolan terdiri dari Komputer (PC), Alat Pendingin (AC), Printer, dan alat penerangan (lampu) yang terhubung dengan terminal listrik yang telah terintegrasi dengan sistem smart office tersebut.

\section{KESIMPULAN}


Pengujian yang dilakukan terhadap pengontrolan lampu, AC, Komputer dan Printer yang terhubung dalam sistem smart office dapat berfungsi dengan baik, sehingga dapat membantu pengontrolan peralatan elekronik yang sedang menyala atau tidak menyala.

\section{UCAPAN TERIMA KASIH}

Terima kasih disampaikan kepada manajemen Politeknik Penerbangan Makassar yang telah mendukung terlaksananya penelitian ini.

\section{DAFTAR PUSTAKA}

Damanik, Irvando, A. (2019). Pengembangan Smart Office berbasis IoT sebagai Penerapan Revolusi Industri 4.0. bblm.go.id/?p=1436, Diakses 3 Juni 2020.

Firdaus. (2014). Wireles Sensor Network, Teori dan Aplikasi. Graha Ilmu Yogyakarta.

Indrawan, I., Prihatin, R., \& Ode Muhammad Makmun, L. . (2018). Marsheller Robotics Program Design at the Makassar Aviation Safety and Engineering Academy. Airman: Jurnal Teknik Dan Keselamatan Transportasi, 1(1), 48-54. https://doi.org/10.46509/ajtk.v1i1.37

Kazem Sohraby, Daniel Minoli and Taieb Znati. (2007). Wireless Sensor Networks, Technology, Protocol, and Application, Wiley \& Sons.

Permana, I.P.A.E. dan Suakanto, S. (2015). Wireless Sensor Network. Informatika Bandung.

Rossydi, A., \& Purbo Wartoyo, B. (2018). Correlation between Emotional Intelligence and Learning Style on Academic Achievement of English Language Students. Airman: Jurnal Teknik Dan Keselamatan Transportasi, 1(1), 5562. https://doi.org/10.46509/ajtk.v1i1.36

Sibarani, M. (2008). Implementasi Sistem Wireless Sensor. Universitas Indonesia.

Sujadi, H. Nurdiana, N. dan Nurbani, F. (2019). Rancang Bangun Prototype Smart Office System Berbasis IOT Pada Building Automation System. Universitas Majalengka.
Suryadi, Adi. Meningkatkan Produktifitas Pegawai Melalui Penerapan Kantor Cerdas (Smart Office). https://setjen.pu.go.id/pusdatin, Diakses 1 Nopember 2020.

Wahid, A.A. Yudhistira. Hanifah (2019). Perancangan Konsep Smart Campus Menggunakan Jaringan Internet of Things. Jurnal Ilmu-ilmu Informatika dan Manajemen STMIK Vol. XX No.X Juni 2019. 